\title{
Association between torus mandibularis, self-reported bruxism and occlusion
}

\author{
Jae-Man Park' and Jong-Mo Ahn ${ }^{2 *}$ \\ ${ }^{1}$ Postgraduate Student, Department of Dentistry, Graduate School, Chosun University, Gwangju, Republic of Korea \\ ${ }^{2}$ Professor, Department of Oral Medicine, School of Dentistry, Chosun University, Gwangju, Republic of Korea
}

This study was conducted to evaluate the association among torus mandibularis (TM), self-reported bruxism, and occlusion. In total, 212 patients with TM (TM group) and 302 patients without TM (control group) who were treated at Chosun University Dental Hospital from January 1, 2019 to April 30, 2019 were included. Self-reported bruxism, Angle's classification of upper and lower 1st molar occlusion, and mandibular lateral movement (canine guidance, group function guidance) were investigated and statistically compared. A significant difference was observed in the relationship between TM and self-reported bruxism in the TM group ( $p<0.001)$. There was no significant difference in the relationship between TM and occlusion in both groups ( $p=0.422)$; however, a significant difference was noted in the relationship between TM and group function guidance in the TM group $(p<0.001)$. There was the association among TM, self-reported bruxism, and group function guidance of mandibular lateral movement.

Key Words: Occlusion, Self-reported bruxism, Torus mandibularis

(c) This is an open-access article distributed under the terms of the Creative Commons Attribution Non-Commercial License (http://creativecommons.org/licenses/by-nc/4.0) which permits unrestricted noncommercial use, distribution, and reproduction in any medium, provided the original work is properly cited.

\section{서 론}

하악골융기는 하악 설면에서 관찰되는 골융기로 20-40세 사 이에 주로 발생되고 임상적으로는 병적인 상태로 고려되지 않 는다[1]. 원인은 명확하지 않지만 유전적 요소, 과도한 교합력, 교합, 이갈이(bruxism), 다양한 치과적 요소 등이 관여한다고 보고되었다[2-4].

이러한 다양한 원인 중 이갈이는 주간 활동이나 수면 기간 중 에 이악물기(teeth clenching)와 같은 단일성 수축이나 이갈이 (teeth grinding)와 같은 율동적인 수축의 형태로 나타나며, 치 아를 마모시켜 교합 상태를 변화시킬 수 있다[5,6]. 또한 이갈이 과정 중에 나타나는 과도한 근육의 활성은 하악골융기나 측두 하악장애(temporomandibular disorders)의 원인으로도 보고
되었다[3,7,8].

이갈이와 같은 이상기능 활동 시에는 하악이 좌, 우측으로 이 동하여 치아에 큰 힘이 가해질 수 있는데, 이러한 측방운동은 치 아나 지지구조에 영향을 끼친다. 이때 교합접촉이 저작계의 기 능에 영향을 미친다고 알려져 있으며 하악골융기와 교합적 요 소(occlusal factor)는 관련이 있다고 보고되었다[9,10].

Morita 등[10]은 하악골융기가 이악물기와 이갈이같은 비기 능적 습관(parafunctional habit)과 관련이 있다고 하였으며, Yoshinaka 등[9]은 하악골융기가 교합력, 그리고 교합과 관련 된 요소들과 연관이 있음을 보고했다.

따라서 본 연구에서는 하악골융기가 이갈이 및 교합의 상태 와 서로 연관성이 있는지 알아보고자 한다.

Received January 29, 2020; Revised March 2, 2020; Accepted March 2, 2020

*Corresponding author: Jong-Mo Ahn, Department of Oral Medicine, School of Dentistry, Chosun University, 309 Pilmun-daero, Dong-gu, Gwangju 61452, Republic of Korea.

Tel: +82-62-220-3890, Fax: +82-62-234-2119, E-mail: jmahn@chosun.ac.kr

Copyright $\odot$ 2020, Oral Biology Research Institute 


\section{대상 및 방법}

\section{연구대상}

2019년 1월 1일부터 2019년 4월 30일까지 조선대학교치과 병원에 내원한 환자 중 골대사와 관련된 질환이 없는 환자 514 명(남자 220명, 여자 294명)을 대상으로 하였다. 본 연구는 조 선대학교치과병원 임상윤리심의위원회의 승인을 받아 진행하 였다(CUDHIRB -1901-007).

\section{연구방법}

\section{하악골융기}

임상검사에서 하악골융기의 존재 여부를 파악하여 하악골융 기가 있는 환자군과 없는 환자군(대조군)으로 분류하여 나이와 성별을 조사하였다. 하악골융기는 하악 좌, 우측 견치, 제 1,2 소 구치 설측 부위에 골의 융기가 존재하는지 여부를 시진과 촉진 을 통해 조사하였으며, 크기와 개수는 조사하지 않았다(Fig. 1).

\section{이갈이}

각각의 군에서 이갈이의 존재 여부를 파악하였으며, 본인이 인지하고 있는 낮과 밤의 이악물기나 이갈이 습관의 존재 여부 와 같이 자는 사람이나 주변 사람들을 통해 습득된 정보를 자가 보고하도록 하였다.

\section{상, 하악 제 1 대구치 교합관계 분류}

상, 하악 제1대구치 교합은 Angle [11]에 의해 보고된 Angle class I, II, III로 분류하였다.

\section{측방 하악운동 분류}

측방 하악운동은 하악이 좌, 우측으로 움직일 때 상, 하악 견 치가 접촉하여 구치부를 이개시키는 견치유도(canine guid-

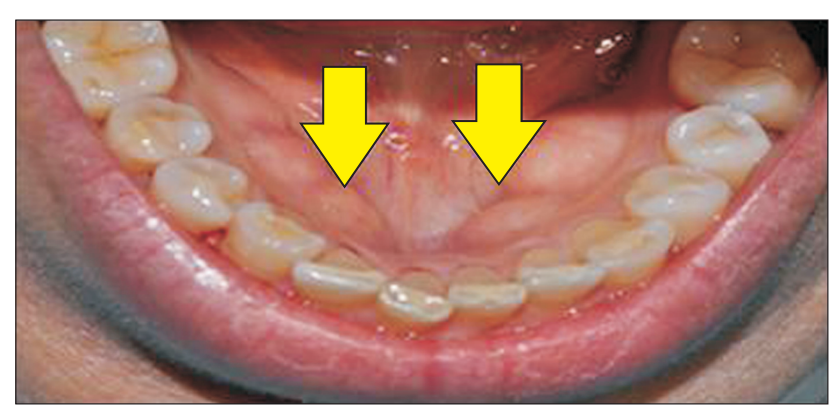

Fig. 1. Tori mandibularis (arrows). ance)와 견치, 소구치와 제1대구치 근심 협측 교두까지 접촉되 는 군기능(group fuction)으로 분류하여 조사하였다.

\section{통계분석}

본 연구에서 사용된 통계 분석법은 SPSS ver. 18.0 (IBM Corp., Armonk, NY, USA)을 이용하였다. 하악골융기가 있는 군과 없는 대조군으로 분류하여 환자의 성별분포와 연령을 분 석하였고, 하악골융기와 이갈이, 하악골융기와 상, 하악 제1대 구치 교합관계, 하악골융기와 측방 하악운동의 상관관계를 비 교 및 분석하기 위해 chi-square test를 사용하였다.

\section{결 과}

\section{환자의 분포}

환자들의 분포를 살펴보면 성별 비율은 하악골융기가 있는 환자군에서 남성 $45.8 \%$, 여성 $54.2 \%$, 대조군에서 남성 $40.7 \%$, 여성 $59.3 \%$ 로 나타났다. 평균연령은 하악골융기가 있는 환자군 이 50.1세, 대조군이 44.2세로 나타났다(Table 1).

\section{하악골융기와 이갈이의 상관관계}

이갈이는 하악골융기가 있는 환자군에서 $33.5 \%$, 대조군에서 $17.2 \%$ 로 나타났으며, 두 군 간의 유의한 차이 $(p<0.001)$ 를 보 였다(Table 2).

\section{하악골융기와 상, 하악 제 1 대구치 교합의 상관관계}

하악골융기가 있는 환자군에서 교합은 I급 $76.9 \%$, II급 $14.6 \%$, III급 8.5\%, 대조군에서 교합은 I급 79.1\%, II급 $10.9 \%$, III급 9.9\%로 나타났으며, 각 군 간의 유의한 차이 $(p=0.422)$ 를

Table 1. Demographic characteristics of the subject

\begin{tabular}{llrc}
\hline \multirow{2}{*}{ Characteristic } & \multicolumn{2}{c}{ Group } \\
\cline { 3 - 4 } & & TM $(\mathbf{n = 2 1 2})$ & Control $(\mathbf{n = 3 0 2})$ \\
\hline \multirow{2}{*}{ Sex } & Male & $97(45.8)$ & $123(40.7)$ \\
\multirow{3}{*}{ Age $(\mathrm{y})$} & Female & $115(54.2)$ & $179(59.3)$ \\
& Male & $51.9 \pm 18.6$ & $42.5 \pm 20.9$ \\
& Female & $48.7 \pm 18.4$ & $45.3 \pm 19.7$ \\
& Total & $50.1 \pm 18.5$ & $44.2 \pm 20.2$ \\
\hline
\end{tabular}

Values are presented as number (\%) or mean \pm standard deviation. TM, torus mandibularis. 
Table 2. Comparison of TM and bruxism in each group

\begin{tabular}{cccccc}
\hline & & \multicolumn{2}{c}{ Group } & & Total \\
\cline { 3 - 4 } & & TM $(\mathbf{n}=\mathbf{2 1 2})$ & Control $(\mathbf{n}=\mathbf{3 0 2})$ & $123(23.9)$ & $\boldsymbol{p}$-value \\
\hline \multirow{2}{*}{ Bruxism } & $\mathrm{O}$ & $71(33.5)$ & $52(17.2)$ & $391(76.1)$ & $<0.001^{*}$ \\
& $\mathrm{X}$ & $141(66.5)$ & $250(82.8)$ & \\
\hline
\end{tabular}

Values are presented as number (\%).

TM, torus mandibularis; $\mathrm{O}$, existence; $\mathrm{X}$, none-existence.

${ }^{*}$ Statistical significance was evaluated by the chi-square test $(p<0.001)$.

Table 3. Comparison of TM and occlusion in each group

\begin{tabular}{|c|c|c|c|c|c|}
\hline & & \multicolumn{2}{|c|}{ Group } & \multirow{2}{*}{$\begin{array}{c}\text { Total } \\
(\mathrm{n}=514)\end{array}$} & \multirow{2}{*}{$p$-value } \\
\hline & & $\mathrm{TM}(\mathrm{n}=212)$ & Control $(n=302)$ & & \\
\hline \multirow[t]{3}{*}{ Occlusion $^{\mathrm{a}}$} & I & $163(76.9)$ & $239(79.1)$ & $402(78.2)$ & 0.422 \\
\hline & II & $31(14.6)$ & $33(10.9)$ & $64(12.5)$ & \\
\hline & III & $18(8.5)$ & $30(9.9)$ & $48(9.3)$ & \\
\hline
\end{tabular}

Values are presented as number (\%).

$\mathrm{TM}$, torus mandibularis.

${ }^{\text {a} A n g l e ' s ~ c l a s s i f i c a t i o n . ~}$

Table 4. Comparison of TM and guidance in each group

\begin{tabular}{llcccc}
\hline & & \multicolumn{2}{c}{ Group } & \multicolumn{2}{c}{ Total } \\
$(\mathbf{n}=\mathbf{5 1 4})$ & P-value \\
\cline { 3 - 4 } & & TM $(\mathbf{n}=\mathbf{2 1 2})$ & Control $(\mathbf{n}=\mathbf{3 0 2})$ & $160(31.1)$ & $<0.001^{*}$ \\
\hline Guidance $^{\mathrm{a}}$ & Canine & $45(21.2)$ & $115(38.1)$ & $354(68.9)$ & \\
\hline
\end{tabular}

Values are presented as number (\%).

$\mathrm{TM}$, torus mandibularis.

${ }^{a}$ Lateral mandibular movement.

${ }^{*}$ Statistical significance was evaluated by the chi-square test $(p<0.001)$.

보이지 않았다(Table 3).

\section{하악골융기와 측방 하악운동의 상관관계}

하악골융기가 있는 환자군에서 견치유도 측방 하악운동은 $21.2 \%$, 군기능 측방 하악운동은 $78.8 \%$, 대조군에서 견치유도 측 방 하악운동은 $38.1 \%$, 군기능 측방 하악운동은 $61.9 \%$ 로 나타났 으며, 군기능 측방 하악운동의 두 군 간 유의한 차이 $(p<0.001)$ 를 보였다(Table 4).

\section{고 찰}

하악골융기는 병적인 상태로 고려되지 않으나 발음에 영향을 끼치거나 연하를 방해할 수도 있으며, 측두하악장애, 구강안면 통증(orofacial pain), 임플란트 치료를 위한 골이식 등과도 연
관되어질 수 있다[3,12,13]. 또한 20-40대에 주로 발생하여 연 령증가에 따라 유병률이 증가하며, 여성보다 남성에서 호발한 다고 보고되었다[1,3,9]. 본 연구에서는 하악골융기가 있는 군과 없는 대조군에서 성별과 나이의 평균값의 차이는 보이지 않았 다(Table 1).

이갈이와 같은 이상기능 활동 시 치아 접촉의 힘과 지속시간 은 기능 활동 시보다 저작계 각 조직에 횔씬 심각한 결과를 초래 한다. Clarke 등[14]은 평균이갈이 강도는 잠들기 전에 최대 이 악물기의 $60 \%$ 정도로, 저작이나 기타 기능 시에 사용되는 정상 적인 힘을 횔씬 초과하기 때문에 이러한 힘은 대단히 큰 정도라 고 하였다. 이갈이는 구강안면 부위에 생리적 내성을 넘어가는 강도의 근육과활성(muscle hyperactivity)을 나타내므로 측두 하악장애나 하악골융기의 발생과 연관되어질 수 있다[2]. 이것 은 이갈이로 인한 과도한 힘이 하악에 스트레스를 가해 하악골 융기 과성장의 원인이 될 수 있음을 의미한다[3]. 
Bertazzo-Silveira 등[15]은 이갈이 증상과 하악골융기 존재 의 관련성에 대한 증거가 충분하지 않다고 하였으나, Nakamura 등[16]은 이악물기와 같은 비기능적 습관과 하악골융기 사이에 통계적으로 의미 있는 관련성을 발견하였으며, Serra와 Campos [17]는 하악골융기가 있는 사람이 없는 사람에 비해 이 갈이를 9.5 배 정도 더 많이 한다고 하였다.

본 연구에서도 대조군에 비해 하악골융기를 가지고 있는 환 자군에서 이갈이가 유의하게 많아 하악골융기의 발생과 이갈이 가 연관되어질 수 있음을 알 수 있었다(Table 3).

정상적으로 하악 제 1 대구치는 상악 제 1 대구치보다 약간 근심 에 위치하지만 일부 환자에서는 이 위치보다 원심이나, 보다 근 심에 위치하는데 Angle [11]은 이러한 차이를 Angle class I, II, III라고 명명하였다[5]. 이러한 치아 접촉점의 차이는 측방 하악 운동 시 좌, 우측 하악 구치(molar)들이 대합치를 가로질러 다른 방향으로 이동할 때 접촉되는 치아의 위치에 영향을 준다.

하악이 좌, 우측으로 이동할 때 치아에 큰 힘이 가해지는데, 이러한 측방운동은 치아나 지지구조에 손상을 줄 수 있으므로 하악과두가 안정된 위치로부터 멀리 있는 치아나 다수의 치아 에 힘이 분산될 수 있는 형태로 일어난다. 길고 큰 치근을 가지 며 치관/치근 비율이 양호한 견치에 의해 측방운동이 일어나는 견치 유도와 견치, 소구치, 간혹 제1대구치 근심 협측교두까지 포함하는 군기능이 견치 유도를 대체할만한 적합한 조건으로 밝혀져 있다. 전체 인구의 약 $26 \%$ 만이 양측성 견치유도를 가지 며, 20-30세 일반인의 $41 \%$ 정도가 군기능 유도를 가지고 있는 것으로 보고되었다[5].

측방운동 시 치아교합면에 마모가 일어나는데, Furtado 등 [18]은 교두(cusps)로부터 퍼져 나오는 힘은 치조골 설면에 전 달되어 치조골융기를 형성시킬 수 있다고 하였다. 강한 교합력 으로 인해 나타나는 교합면 마모는 하악골융기의 형성과 발달 에 깊은 관련이 있고, 교합으로 인한 치아의 마모나 잘 발달된 저작근육은 하악골융기의 원인이 된다고 보고되었다[19,20].

Shiho 등[21]은 구치의 마모와 하악골융기 형성은 관련성이 크다고 하였고, Yoshinaka 등[9]은 하악골융기와 교합적 요소 는 관련이 있다고 보고했다.

본 연구에서는 Angle에 의한 구치부 교합과 하악골융기의 연 관성은 없었지만(Table 3), 측방 하악운동 시 하악골융기를 가 지고 있는 환자의 군기능을 하는 환자군에서 통계적인 유의성 을 보여 치아의 접촉과 관련된 교합요소가 하악골융기와 관련 이 있음을 알 수 있었다(Table 4). 이러한 결과는 제 1 대구치 치 아 접촉과 같은 단순요소보다는 이갈이와 같은 비기능적인 습 관이 있으며 측방 하악운동 시 군기능과 같은 치아 접촉이 많은 요소가 하악골 형성과 발달에 관여한다는 선행 연구들의 결과 와 일치한다[15].
본 연구는 하악골융기가 이갈이 및 교합의 상태와 서로 연관 성이 있는지를 알아보기 위해 하악골융기가 있는 환자군과 대 조군에서 이갈이의 존재여부, 상, 하악 제 1 대구치의 교합관계 및 측방 하악운동의 형태를 조사하였다. 이갈이는 하악골융기 가 있는 환자군에서 더 많이 나타났으며 통계적인 유의성을 나 타냈다. 하악골융기와 상, 하악 제 1 대구치의 교합과는 연관성이 없었으나 측방 하악운동 시 군기능을 하는 환자군에서 하악골 융기는 통계적인 유의성을 나타냈다. 따라서 하악골융기의 발 생은 과도한 교합력을 나타내는 이갈이와 측방 하악운동 시 여 러 개의 치아에 의해 유도되는 군기능과 연관성이 있음을 알 수 있다.

\section{ACKNOWLEDGEMENTS}

This study was supported by research fund from Chosun University Dental Hospital, 2019.

\section{CONFLICTS OF INTEREST}

The authors declare that they have no competing interests.

\section{ORCID}

\author{
Jae-Man Park \\ https://orcid.org/0000-0002-4817-8890 \\ Jong-Mo Ahn \\ https://orcid.org/0000-0002-3615-3688
}

\section{REFERENCES}

1. Lee KH, Lee JH, Lee HJ. Concurrence of torus mandibularis with multiple buccal exostoses. Arch Plast Surg 2013;40:466-468. doi: 10.5999/aps.2013.40.4.466.

2. Auškalnis A, Rutkūnas V, Bernhardt O, Šidlauskas M, Šalomskienė L, Basevičienè N. Multifactorial etiology of torus mandibularis: study of twins. Stomatologija 2015; $17: 35-40$.

3. Sirirungrojying S, Kerdpon D. Relationship between oral tori and temporomandibular disorders. Int Dent J 1999;49:101104. doi: 10.1111/j.1875-595x.1999.tb00516.x.

4. Morrison MD, Tamimi F. Oral tori are associated with local mechanical and systemic factors: a case-control study. J Oral Maxillofac Surg 2013;71:14-22. doi: 10.1016/ j.joms.2012.08.005.

5. Okeson JP. Management of temporomandibular disorders and occlusion. 7th ed. St. Louis: Mosby; 2003;141-176. 
6. Firmani M, Reyes M, Becerra N, Flores G, Weitzman M, Espinosa P. [Sleep bruxism in children and adolescents]. Rev Chil Pediatr 2015;86:373-379. doi: 10.1016/ j.rchipe.2015.05.001. Spanish.

7. Sierwald I, John MT, Schierz O, Hirsch C, Sagheri D, JostBrinkmann PG, Reissmann DR. Association of temporomandibular disorder pain with awake and sleep bruxism in adults. J Orofac Orthop 2015;76:305-317. doi: 10.1007/ s00056-015-0293-5.

8. Clifford T, Lamey PJ, Fartash L. Mandibular tori, migraine and temporomandibular disorders. Br Dent J 1996;180:382384. doi: 10.1038/sj.bdj.4809094.

9. Yoshinaka M, Ikebe K, Furuya-Yoshinaka M, Maeda Y. Prevalence of torus mandibularis among a group of elderly Japanese and its relationship with occlusal force. Gerodontology 2014;31:117-122. doi: 10.1111/ger.12017.

10. Morita K, Mori T, Maruyama M, Hiraoka A, Higa C, Kuroki A, Yoshida M, Tsuga K. Association between buccal mucosa ridging and oral or occlusal status among older people. Oral Dis 2018;24:778-783. doi: 10.1111/odi.12828.

11. Angle EH. Classification of malocclusion. Dent Comos 1899;41:248-264.

12. Morita K, Tsuka H, Shintani T, Yoshida M, Kurihara H, Tsuga K. Prevalence of torus mandibularis in young healthy dentate adults. J Oral Maxillofac Surg 2017;75:2593-2598. doi: 10.1016/j.joms.2017.04.044.

13. Moraes Junior EF, Damante CA, Araujo SR. Torus palatinus: a graft option for alveolar ridge reconstruction. Int J Periodontics Restorative Dent 2010;30:283-289. doi: 10.11607/prd.00.0921.

14. Clarke NG, Townsend GC, Carey SE. Bruxing patterns in man during sleep. J Oral Rehabil 1984;11:123-127. doi: 10.1111/j.1365-2842.1984.tb00561.x.

15. Bertazzo-Silveira E, Stuginski-Barbosa J, Porporatti AL, Dick B, Flores-Mir C, Manfredini D, De Luca Canto G. Association between signs and symptoms of bruxism and presence of tori: a systematic review. Clin Oral Investig 2017;21:2789-2799. doi: 10.1007/s00784-017-2081-7.

16. Nakamura K, Masumi S, Andoh S, Takeuchi T, Kubo M, Yasumoto K, Kanetou T. Relationships between mandibular torus and occlusal force, occlusal contact area and parafunction. J Kyushu Dent Soc 2007;61:77-81. doi: 10.2504/ kds.61.77.

17. Serra V de BR, Campos MI da C. [Correlação entre bruxismo e tórus mandibular e palatino: caso clínico]. Rev Serv ATM 2005;5:60-63. Portuguese.

18. Furtado ACN, Leite AK de M, [Albuquerque RA de, Sobral APV. The correlation between the presence of exostoses and temporomandibular joint dysfunction]. Rev Bras Promoç Saúde 2008;21:174-179. Portuguese.

19. Igarashi Y, Ohzeki S, Uesu K, Nakabayashi T, Kanazawa E. Frequency of mandibular tori in the present-day Japanese. Anthropol Sci 2008;116:17-32. doi: 10.1537/ase.050613.

20. García-García AS, Martínez-González JM, Gómez-Font R, Soto-Rivadeneira A, Oviedo-Roldán L. Current status of the torus palatinus and torus mandibularis. Med Oral Patol Oral Cir Bucal 2010;15:e353-e360. doi: 10.4317/medoral.15.e353.

21. Shiho T, Masami M, Tatsuhiko Y, Takehiro T, Yasuo M, Kaoru S. Survey of attrition and bone torus based on the observation of study casts. J Tokyo Dent Coll Soc 2000; 100:203-209. 